Research paper

\title{
Immunological changes in canine peripheral blood leukocytes triggered by immunization with first or second generation vaccines against canine visceral leishmaniasis
}

\author{
Márcio Sobreira Silva Araújo ${ }^{\mathrm{a}, \mathrm{b}}$, Renata Aline de Andrade ${ }^{\mathrm{a}}$, Renato Sathler-Avelar ${ }^{\mathrm{a}}$, \\ Camila Paula Magalhães ${ }^{a}$, Andréa Teixeira Carvalho ${ }^{a}$, Mariléia Chaves Andrade ${ }^{a, g}$, \\ Sabrina Sidney Campolina ${ }^{\mathrm{b}}$, Maria Norma Mello ${ }^{\mathrm{c}}$, Leonardo Rocha Vianna ${ }^{\mathrm{d}}$, \\ Wilson Mayrink ${ }^{\mathrm{c}}$, Alexandre Barbosa Reis ${ }^{\mathrm{e}}$, Luiz Cosme Cotta Malaquias ${ }^{\mathrm{f}}$, \\ Luciana Morais Rocha ${ }^{a}$, Olindo Assis Martins-Filho ${ }^{\mathrm{a}, *}$

\footnotetext{
a Laboratório de Biomarcadores de Diagnóstico e Monitoração, Centro de Pesquisas René Rachou, Fundação Oswaldo Cruz, Av. Augusto de Lima, 1715 Barro Preto, Belo Horizonte, Minas Gerais, 30190-002, Brazil

b Laboratório de Imunologia, Centro de Pesquisas René Rachou, Fundação Oswaldo Cruz, Av. Augusto de Lima, 1715 Barro Preto, Belo Horizonte, Minas Gerais, 30190-002, Brazil

c Departamento de Parasitologia, Instituto de Ciências Biológicas, Universidade Federal de Minas Gerais, Avenida Antônio Carlos, 6627, Belo Horizonte, Minas Gerais, 31270-901, Brazil

d $4^{\circ}$ Cia da Polícia Militar de Minas Gerais - PMMG, Rua Padre Feijó, 917, Belo Horizonte, Minas Gerais, 30285-350, Brazil

e Laboratório de Imunopatologia, NUPEB, Departamento de Análises Clínicas, Escola de Farmácia, Universidade Federal de Ouro Preto, Rua Costa Sena s/n, Ouro Preto, Minas Gerais, 35400-000, Brazil

f Departamento de Ciências Biomédicas, Universidade Federal de Alfenas, Rua Gabriel Monteiro da Silva, 700, Alfenas, Minas Gerais, 37130-000, Brazil

g Departamento de Fisiopatologia, CCBS, Unimontes, Montes Claros, Minas Gerais, 39401-089, Brazil
}

\section{A R T I C L E I N F O}

\section{Article history:}

Received 28 July 2010

Received in revised form 3 February 2011

Accepted 14 February 2011

\section{Keywords:}

Leishmaniasis canine

Leishvaccine

Leishmune $^{\circledR}$

Immunophenotyping

Cytokines

Nitric oxide

\begin{abstract}
A B S T R A C T
In this study, we summarized the major phenotypic/functional aspects of circulating leukocytes following canine immunization with Leishvaccine and Leishmune ${ }^{\circledR}$. Our findings showed that Leishvaccine triggered early changes in the innate immunity (neutrophils and eosinophils) with late alterations on monocytes. Conversely, Leishmune ${ }^{\circledR}$ induced early phenotypic changes in both, neutrophils and monocytes. Moreover, Leishvaccine triggered mixed activation-related phenotypic changes on T-cells $\left(\mathrm{CD}^{+}\right.$and $\left.\mathrm{CD} 8^{+}\right)$and $\mathrm{B}-$ lymphocytes, whereas Leishmune ${ }^{\circledR}$ promoted a selective response, mainly associated with $\mathrm{CD}^{+} \mathrm{T}$-cell activation. Mixed cytokine profile (IFN- $\left.\gamma / \mathrm{IL}-4\right)$ was observed in Leishvaccine immunized dogs whereas a selective pro-inflammatory pattern (IFN- $\gamma / \mathrm{NO}$ ) was induced by Leishmune ${ }^{\circledR}$ vaccination. The distinct immunological profile triggered by Leishvaccine and Leishmune ${ }^{\circledR}$ may be a direct consequence of the distinct biochemical composition of these immunobiological, i.e. complex versus purified Leishmania antigen along with Bacillus Calmette-Guérin (BCG) versus saponin adjuvant. Both immunobiologicals are able to activate phagocytes and $\mathrm{CD}^{+} \mathrm{T}$-cells and therefore could be considered as a putative vaccines against canine visceral leishmaniasis (CVL).
\end{abstract}

(C) 2011 Elsevier B.V. All rights reserved.
* Corresponding author at: Avenida Augusto de Lima 1715, Barro Preto, Belo Horizonte - Minas Gerais, CEP: 30190-002, Brazil.

Tel.: +55 2131 33497764; fax: +55 213132953115 .

E-mail address: oamfilho@cpqrr.fiocruz.br (O.A. Martins-Filho).

\section{Introduction}

The visceral leishmaniasis is a disease in high expansion throughout the world, especially in Brazil. The vertebrates hosts recognized as reservoirs are limited to mammals 
belonging to the family Canidae, being dogs the most relevant reservoir. The canine visceral leishmaniasis (CVL) is clinically characterized by a wide-ranging clinical signs related to high anti-leishmanial antibody levels and lack of a cell-mediated response. Leishmania are intracellular parasites and, under immunodeficiency conditions, they multiply and migrate from lymphoid tissue to other organs, displaying severe clinical and pathological changes which could lead to animal death (Reis et al., 2010).

The large number of CVL cases and the intense skin parasitism make them the main source of sand fly vectors infection and therefore to humans, featuring an antropozoonotic profile of the disease (Abranches et al., 1991; Moreno and Alvar, 2002). Therefore the current strategy for managing the disease control is based on seropositive dogs elimination, as well as a systematic treatment of human cases and vector control (Tesh, 1995).

Despite of dog's euthanasia is the major strategy for disease control, it is not widely acceptable, mainly by dog owners (Dantas-Torres, 2006). However, most studies focusing on dog therapeutic strategies have failed to achieve a consistent parasitological cure in CVL (Noli and Auxilia, 2005; Baneth and Shaw, 2002). In this context, the development of a protective vaccine against CVL is a promising tool to CVL control and also in human visceral leishmaniasis (Gradoni, 2001; Dantas-Torres, 2006). In last decades several anti-CVL vaccine candidates have been proposed. These formulations include live/killed Leishmania parasites (crude parasite extract/first-generation), purified Leishmania antigens or live recombinant bacteria expressing Leishmania antigens (purified antigens/second generation) as well as antigen-encoding DNA plasmids (third generations) (Gradoni, 2001; Palatnik-de-Sousa, 2008). Two Brazilian research groups developed two vaccines against CVL of first and second generation, called Leishvaccine and Leishmune ${ }^{\circledR}$ showing relevant results. The last one, composed of fucose mannose ligand (FML) purified fraction from Leishmania donovani promastigotes plus saponin as adjuvant, have been licensed in Brazil and become commercially available. Studies demonstrated that both Leishvaccine and Leishmune ${ }^{\circledR}$ are capable of triggering protective immune response when experimental animals are challenge with Leishmania after vaccination (da Costa et al., 1992; Palatnik de Sousa et al., 2001; Mayrink et al., 2002; Borja-Cabrera et al., 2004). Regardless both immunobiologicals have been shown to elicit putative protection against CVL, the precise immunological events underlying the immunoprophylactic mechanisms remain to be elucidated and still require extensive investigation. There is generally a consensus that the cytokine microenvironment plays a central role in Leishmaniasis pathogenesis outcome (Vanloubbeeck and Jones, 2004; Barbiéri, 2006; Carrillo and Moreno, 2009). Immunological studies have shown that a type- 1 response is crucial to the establishment of protective mechanism and control the pathogenesis of Leishmania infection, whereas activation of type-2 cytokine profile results in the progression of the disease. In murine model, IFN- $\gamma$ and IL- 4 have been already reported as a relevant hallmarks of these two poles of the immune response, as they are associated with protection and susceptibility to Leishmania infection, respectively
(Aguilar-Torrentera and Carlier, 2001). The main effector mechanism involved in protective immune response in dogs infected with Leishmania is macrophage activation by IFN- $\gamma$ to kill intracellular amastigote parasite forms mediated by nitric oxide production (Pinelli et al., 2000). In this context, immunobiologicals based on Leishmania antigens can be used to elicit the protective type 1 immune response which is a pre-requisite to create a successful CVL vaccine.

Herein we have characterized the phenotypic and functional aspects of peripheral blood leukocytes after different vaccination protocols with Leishvaccine and Leishmune ${ }^{\circledR}$. The aim of the current study was to investigate, using a cross-sectional methodology, the cytokine profile of circulating T-cell subsets, besides the level of nitric oxide synthesis by peripheral blood monocytes after Leishvaccine and Leishmune ${ }^{\circledR}$ vaccination.

\section{Materials and methods}

\subsection{Animals and vaccination regimens}

This study was approved by the Ethical Committee for the use of Experimental Animals of the Fundação Oswaldo Cruz, Brazil (CEUA - P-01/09-4). All procedures in this study were according to the guidelines set by the Brazilian Animal Experimental College (COBEA). Prior all animals were treated for intestinal helminthic infections and immunized against parvovirosis, leptospirosis, distemper, parainfluenza and hepatitis. All animals have received unrestricted access to balanced food (Purina ${ }^{\circledR}$, São Paulo, Brazil) and water given ad libitum and were maintained in quarantine before the inclusion in the study. The dogs inclusion criteria were negative serological results in the enzyme-linked immunosorbent assay (ELISA, Biomanguinhos, FIOCRUZ, RJ, Brazil) for CVL used as a reference standard diagnosis test. Following these criteria, twenty four healthy German shepherd dogs (16 males and 8 females), age ranging from 18 to 60 months [18 months ( 4 males and 4 females), 30 months ( 3 males and 2 females), 42 months ( 5 males) and 66 months (4 males and 2 females)] were included in this study and maintained at the kennel of Minas Gerais Militar Police, Brazil during the entire experimental procedures. Dogs were divided into two groups named Leishvaccine and Leishmune ${ }^{\circledR}$. Dogs in the Leishvaccine group (8 males and 4 females, with age ranging from 18 to 66 months) were immunized throughout a complete vaccination regimen that included three subcutaneous doses of the vaccine with an interval of 21 days between each. The first dose corresponded to $0.6 \mathrm{~mL}$ of Leishvaccine ( $360 \mu \mathrm{g}$ of protein) plus $0.4 \mathrm{~mL}$ of Bacillus Calmette-Guérin-BGC ( $400 \mu \mathrm{g}$ of protein) as adjuvant. The second dose corresponded to $0.6 \mathrm{~mL}$ of Leishvaccine ( $360 \mu \mathrm{g}$ of protein) plus $0.3 \mathrm{~mL}$ of BGC (300 $\mu \mathrm{g}$ of protein) as adjuvant. The third dose corresponded to $0.6 \mathrm{~mL}$ of Leishvaccine ( $360 \mu \mathrm{g}$ of protein) plus $0.2 \mathrm{~mL}$ of BGC (200 $\mu$ g of protein) as adjuvant.

The animals vaccinated with Leishmune ${ }^{\circledR}$ ( 8 males and 4 females, with age ranging from 18 to 66 months), that has saponin as adjuvant, had a complete vaccination regimen as recommended by the manufacturer (FortDodge ${ }^{\circledR}$, Campinas, SP, Brazil), which included three subcutaneous doses 
of $1 \mathrm{~mL}$ of vaccine with an interval of 21 days between each dose.

\subsection{Immunobiological tools}

Leishvaccine consisted of Leishmania (L.) amazonensis (strain IFLA/BR/1967/PH8) antigenic preparation obtained as described by Mayrink et al. (1996) and using BCG as adjuvant (Fundação Ataulfo de Paiva, RJ, Brazil).

The Leishmune ${ }^{\circledR}$ was composed of lyophilized Leishmania donovani purified fucose mannose ligand-FML (1.5 mg) and saponin as adjuvant $(0.5 \mathrm{mg})$ and was reconstituted in $1 \mathrm{~mL} \mathrm{NaCl} 0.9 \%$ sterile saline solution and administered subcutaneously. The Leishmune ${ }^{\circledR}$ is registered as a Patent: INPI number: PI1100173-9 (18.3.97). Federal University of Rio de Janeiro, Brazil.

\subsection{Blood samples}

The samples were collected from the radial vein by trained professional at the kennel of the $4^{\circ}$ Cia da Polícia Militar de Minas Gerais, Brazil. Peripheral blood samples $(5 \mathrm{~mL})$ were collected in vacutainer tubes containing EDTA as anticoagulant in four consecutive periods, referred as: before vaccination (T0) and after the 1st (T1), 2nd (T2) and 3rd (T3) dose of each vaccine. The blood samples were always obtained 7 days after each dose, in order to investigate the immunological events triggered after each immunization procedure. Additional blood samples $(10 \mathrm{~mL})$ were collected using vacutainer tubes with sodium heparin at T0 and 40 days after the last dose (T4). The samples were maintained at room temperature from $1 \mathrm{~h}$ and up to $12 \mathrm{~h}$ prior to processing.

\subsection{Monoclonal antibodies}

Monoclonal antibodies to cell surface markers able to indentify major and minor leukocytes subsets have become available for studies in canine models. In this study we have elect a set of such cell surface marker considering relevant in the context of immunoprophylaxis against CVL, including CD4 to identify canine neutrophils, CD14 to quantity the monocytes, CD3, CD4, CD5 and CD8 to analyze T-cell subsets, CD21 to identify B-cells. The expression of CD4 by canine neutrophils is without precedent in other mammalian species; the functional significance of neutrophil CD4 expression is still puzzling in the light of the current understanding of the functions of CD4 as the receptor for non-polymorphic regions of $\mathrm{MHCII}$ molecules (Moore et al., 1992). The analysis of these leukocytes subpopulations was performed by flow cytometry, using a range of fluorescent labeled monoclonal antibodies, including anti-canine CD3-RPE 1:10 (mouse IgG1, clone CA17.2A12), anti-canine CD4-FITC or RPE 1:320 (rat IgG2a, clone YKIX302.9), anti-canine CD5-FITC 1:160 (rat IgG2a, clone YKIX322.3), anti-canine CD8-FITC or RPE 1:40 (rat IgG1, clone YCATE55.9), anti-human CD14-PE-Cy5 1:40 (mouse IgG2a, clone TuK4) and anti-canine CD21-RPE (B-cell) 1:160 (mouse IgG1, clone CA2.1D6). Several cell surface markers related to immune activation, cellular migration and regulatory events have been well described in several mammalians hosts (Barclay et al., 1997).

Monoclonal antibodies to cell surface markers related to activation, migration and immunoregulation events have become available for studies in canine models. In this study we have elect a set of such cell surface marker considering relevant in the context of immunoprophylaxis against CVL, including CD18, CD32 and MHCII. The CD18 cell surface antigen is virtually expressed by all leukocytes, but more strongly upon monocytes and granulocytes than upon lymphocytes. The expression of this molecule is mostly involved in cell adhesion, migration and chemotaxis. The CD32 is a cell surface receptor for IgG Fc portion expressed by monocytes, granulocytes and B-cells and mediates several immunological functions including phagocytosis and immunomodulation of IgG secretion by B-cells. The MHCII molecules are relevant cell surface markers that participate in the presentation of extracellular antigen and mediate the cell-cell interaction with $\mathrm{CD} 4^{+} \mathrm{T}$ cells. Particularly in the dog immune system, all peripheral blood leukocytes (PBL) including all T-cells, B-lymphocytes and macrophages express MHCII (Cobbold and Metcalfe, 1994). In the present investigation, this select set of cell surface marker was used to explore the events of activation, cellular migration and immunoregulation anti-CVL vaccination, using anti-canine MHCII-FITC 1:80 (rat IgG2a, clone YKIX334.2), anti-human cross-reactive with canine CD18RPE 1:6 (rat IgG2b, clone YFC118.3) and anti-human cross reactive with CD32-FITC 1:6 (mouse IgG1, clone AT10), respectively.

Additionally, mAbs cross-reactive with canine cytokines were used for intracytoplasmic staining, including antibovine IFN- $\gamma$-PE (clone CC302) and anti-bovine IL-4-PE (clone CC303), all purchased from Serotec (Oxford, UK).

It is relevant to note that all anti-human and anti-mouse antibodies used in our study have dog's cross reactivity as described by manufactory.

\subsection{Canine blood leukocytes immunophenotyping}

Flow cytometric immunophenotyping analyses were carried out using the peripheral blood collected with EDTA from all animals included in this study $(n=24)$. Samples collected at T0, T1, T2 and T3 were processed as follow: $30 \mu \mathrm{L}$ of each sample and the same volume of fluorochromelabeled anti-canine cell surface marker mAbs previously diluted in PBS-0.5\%BSA (phosphate buffered saline $0.15 \mathrm{M}$, $\mathrm{pH} 7.2$ supplemented with $0.5 \%$ of bovine serum albumin and $0.1 \%$ of sodium azide) were incubated for $30 \mathrm{~min}$ at room temperature (RT) protected from light. After that, the erythrocytes were lysed by adding $3 \mathrm{~mL}$ of lysis solution (FACS brand lysing solution; Becton Dickinson San Diego, CA, USA) followed by incubation for $10 \mathrm{~min}$ at RT. The leukocytes were then washed twice with $2 \mathrm{~mL}$ of PBS (phosphate buffered saline $0.15 \mathrm{M}, \mathrm{pH} 7.2$ ) and centrifuged at $400 \times g$ for $10 \mathrm{~min}$ at RT. Then, the labeled cells were fixed for $30 \mathrm{~min}$ at RT, with $200 \mu \mathrm{L}$ of FACS FIX solution ( $10 \mathrm{~g} / \mathrm{L}$ paraformaldehyde; $10.2 \mathrm{~g} / \mathrm{L}$ sodium cacodylate and $6.65 \mathrm{~g} / \mathrm{L}$ sodium chloride, $\mathrm{pH}$ 7.2) The processed samples were stored at $4-8{ }^{\circ} \mathrm{C}$ up to $24 \mathrm{~h}$ before cytofluorometric analysis. Each assay included an internal control for 
autofluorescence in which the cells were incubated in the presence of PBS-0.5\%BSA. Flow cytometric measurements were performed on a FACScan instrument (Becton Dickinson, Moutain View, CA) interfaced to an apple G3 FACStation. The Cell-Quest software package was used in both data acquisition and analysis. A total of 10,000 events were acquired for each preparation. Distinct gating strategies were used to select the leukocytes subpopulation as proposed by Reis et al. (2005) and Fujiwara et al. (2005). The canine neutrophils were identified and selected based on their unique expression of CD4 cell surface marker, using FL1/anti-CD4 FITC versus SSC dot plot distributions as illustrated in Fig. 1A. The eosinophils were identified and selected based on their autofluorescence property, using non-related FL-3 channel versus FSC dot plot distributions as illustrated in Fig. 1B. Backgate strategy was further used to confirm the selection of eosinophils on FSC versus SSC dot plot distribution (Fig. 1B, inserted plot). A specific gating strategy using anti-CD14 RPE-Cy5 versus SSC dot plot distribution was applied to select monocytes, identified as SSC ${ }^{\text {Low }}$ CD14 ${ }^{\text {High }}$ cells as illustrated in Fig. 1C. The lymphocyte population was identified and selected based on their morphometric (low size and low granularity) using FSC versus SSC dot plot distribution as illustrated in Fig. 1D. Following the gating strategies to select the specific leuko- cyte subset, the phenotypic analysis was carried out using complementary fluorescence spectra profiles. The results were expressed as percentage of positive cells within the selected gate for cell surface markers presenting bimodal distribution as illustrated for the analysis of CD32 expression by monocytes (Fig. 1E). On the other hand, the analysis of cell surface markers presenting unimodal distribution was reported in mean fluorescence intensity (MFI) on log scale as illustrated for the unique expression of MHCII for all canine lymphocytes (Fig. 1F).

\subsection{L. chagasi soluble antigen (SLA)}

Leishmania chagasi promastigote forms (MHOM/BR/1972/BH46) were grown in liver infusion tryptose medium (LIT), supplemented with $10 \%$ of fetal bovine serum (Camargo, 1964) at $24^{\circ} \mathrm{C}$. Stationary-phase parasites (8 days of growth) were transferred to $50 \mathrm{~mL}$ polypropylene tubes (Falcon, Becton Dickinson, San Diego) and submitted to differential centrifugation $(100 \times \mathrm{g}$, $10 \mathrm{~min}$, room temperature) to remove remaining clusters of parasites. The supernatant was left to rest for $10 \mathrm{~min}$ at room temperature. The single-cell parasite suspension was transferred to another $50 \mathrm{~mL}$ polypropylene tube and spin down at high speed $(1000 \times \mathrm{g})$ for $10 \mathrm{~min}$ at $4-8{ }^{\circ} \mathrm{C}$.

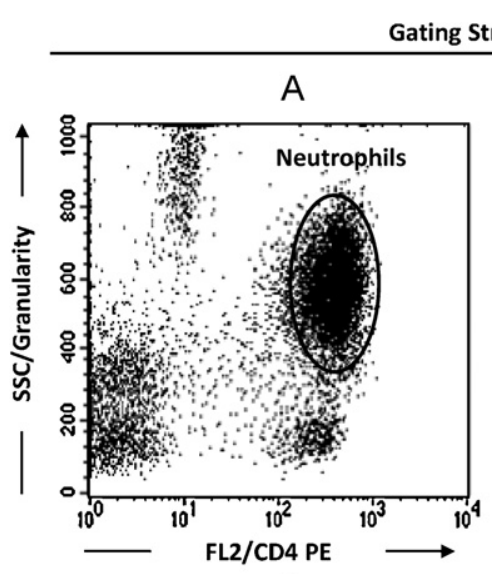

Gating Strategies

Immunophenotype Profile
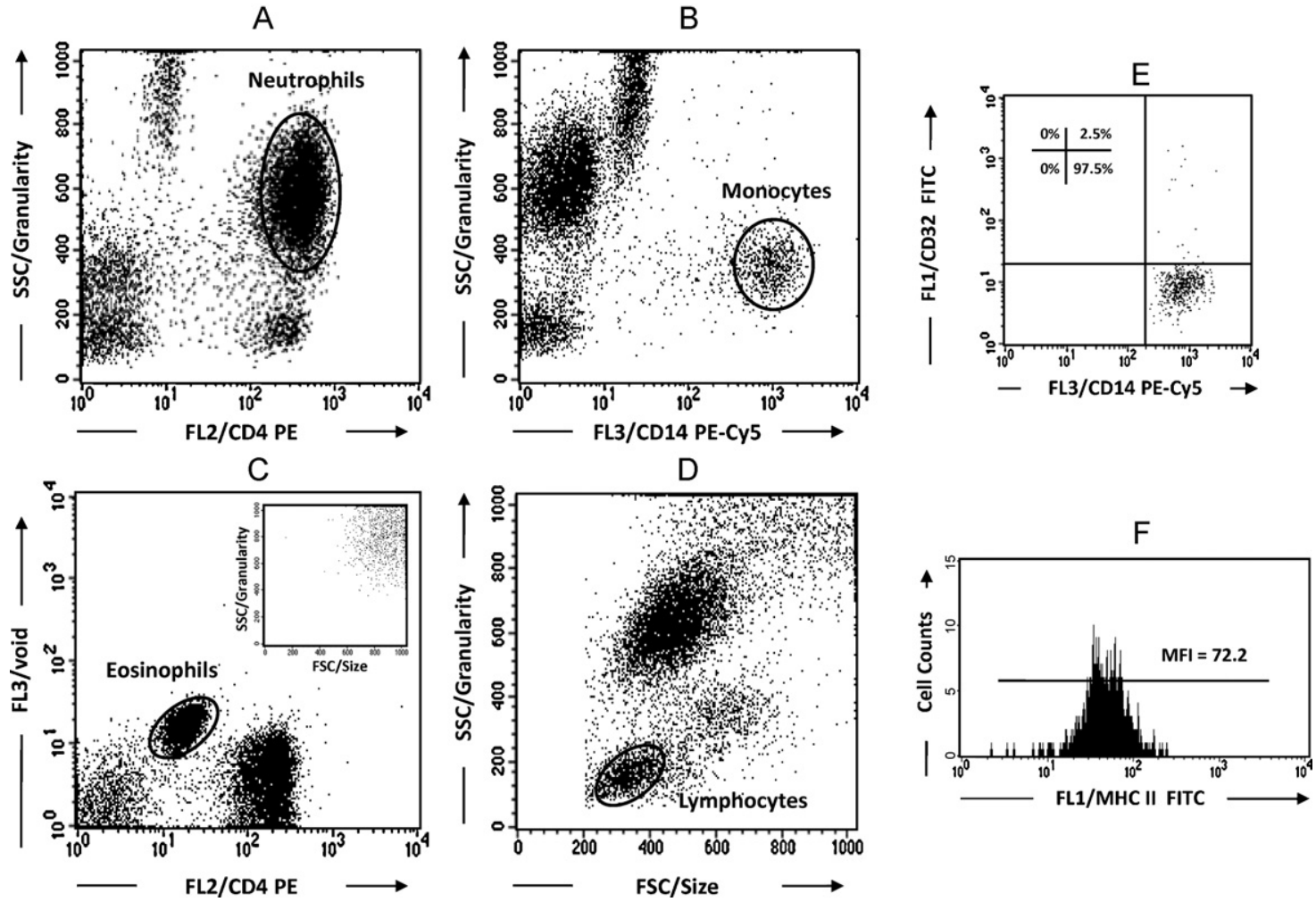

Fig. 1. Gating strategies used to select specific leukocytes subpopulation including neutrophils identified as CD4 ${ }^{+}$SSC ${ }^{\text {High }}$ events $(A)$, eosinophils known by their autofluorescence profile distributed along $45^{\circ}$ cell cluster on bi-dimensional fluorescence dot plots (B) and confirmed by their SSCHigh pattern on FSC versus SSC distribution (C, inserted plot), monocytes selected as CD14 ${ }^{\text {High }}$ SSC $^{\text {Intermediate }}$ cells (C) and lymphocyte selected based on their FSC ${ }^{\text {Low }}$ SSC ${ }^{\text {Low }}$ morphometric feature on FSC versus SSC dot plot distribution. Following the gate setup procedures, the phenotypic analysis was carried to determine the percentage of positive cells for cell phenotypes with bimodal distribution (E) and mean fluorescence intensity for cell markers displaying unimodal distribution (F). 
The supernatant was discarded and the pellet washed twice $\left(1000 \times g, 10 \mathrm{~min}, 4-8^{\circ} \mathrm{C}\right)$ with phosphate buffered saline: PBS (0.15 M, pH 7.2). After the washing steps, the single-cell $L$. chagasi promastigote suspension was stored at $-70^{\circ} \mathrm{C}$ until use. The frozen pellet was then thawed, resuspended into equal volume of cold PBS and submitted to three ultra-sound cycles of $1 \mathrm{~min}$ at $40 \mathrm{~W}$ on ice bath (Sonifier Cell Disruptor ${ }^{\circledR}$ - Branson Sonic Power Co., EUA). The sonicated material was centrifuged at $50,000 \times g$ for $1 \mathrm{~h}$ and $30 \mathrm{~min}$ at $4{ }^{\circ} \mathrm{C}$. The supernatant was transferred to dialysis tubes and dialyzed through PBS for $24 \mathrm{~h}$, and submitted to three PBS changes in every $6 \mathrm{~h}$. The dialyzed soluble antigen was filtered in $0.22 \mu \mathrm{m}$ disposable syringe sterile filters of under aseptic conditions. One aliquot was taken for protein quantification by the method described by Lowry et al. (1951). The final protein concentration was adjusted to $1000 \mu \mathrm{g} / \mathrm{mL}$. Antigen preparation was stored in $100 \mu \mathrm{L}$ aliquots at $-70^{\circ} \mathrm{C}$ prior the use in the in vitro cultures of peripheral blood mononuclear cells.

\subsection{Canine peripheral blood mononuclear cells isolation and culture}

Peripheral blood mononuclear cells (PBMC) were isolated from blood samples collected in heparin tubes previously diluted in equal volume of RPMI 1640 (Gibco, Grand Island, NY, USA) separated by a density gradient (Ficoll-Hypaque Histopaque ${ }^{\circledR}$ 1.077; Sigma Chemical Co.) centrifuged at $700 \times g$ for $40 \mathrm{~min}$ at RT. The PBMC were collected from the interface between the top plasma layer and the Ficoll-Hypaque column. Cells were than washed twice with RPMI $1640(600 \times \mathrm{g}$, for $10 \mathrm{~min}$, at RT), counted and resuspended in RPMI 1640 at $1 \times 10^{7}$ cells $/ \mathrm{mL}$.

The culture assays were performed in 24-well flatbottomed tissue culture plates (Corning, New York, NY, USA), each well containing $800 \mu \mathrm{L}$ of cell culture medium comprising of RPMI 1640 supplemented with streptomycin $(100 \mathrm{mg} / \mathrm{mL})$, penicillin $(100 \mathrm{U} / \mathrm{mL})$, L-glutamine $(2 \mathrm{mM})$, $\beta$-mercaptoethanol $\left(5 \times 10^{-5} \mathrm{M}\right)$ and fetal bovine serumFBS (10\%). Aliquots of $100 \mu \mathrm{L}$ of the PBMC suspension $\left(1 \times 10^{6}\right.$ cells/well $)$ were added in wells following the addition of $100 \mu \mathrm{L}$ of RPMI 1640 (control cultures, CC) or $100 \mu \mathrm{L}$ of soluble $L$. chagasi antigen (SLA) at final concentration $25 \mu \mathrm{g} / \mathrm{mL}$ (stimulated cultures-SLA). Cultures were submitted to incubation in $5 \% \mathrm{CO}_{2}$ humidified incubator, at $37^{\circ} \mathrm{C}$, for 5 days. Brefeldin A-BFA (Sigma, St Louis, MO, USA) was added to each well at final concentration of $10 \mu \mathrm{g} / \mathrm{mL}$ and cultures submitted to an additional period of $4 \mathrm{~h}$ of incubation in $5 \% \mathrm{CO}_{2}$ humidified incubator, at $37^{\circ} \mathrm{C}$, for 5 days. At the end of incubation periods, all cultures were treated with EDTA (Sigma, St Louis, MO, USA) at a final concentration of $2 \mathrm{mM}$ for $15 \mathrm{~min}$, at RT. The experiment was performed in quadruplicates.

\subsection{Intracellular cytokines immunostaining}

EDTA-treated PBMC cultures were washed once with FACS buffer prepared as PBS supplemented with $0.5 \%$ of bovine serum albumin-BSA (Sigma, St Louis, MO, USA) by centrifugation at $600 \times g$ for $7 \mathrm{~min}$ at RT. Cell pellet was resuspended with $400 \mu \mathrm{L}$ of FACS buffer and $200 \mu \mathrm{L}$ aliquots incubated in $5 \mathrm{~mL}$ polystyrene tubes (Becton Dickinson, Frankling Lakes, NJ, USA) in the presence of $60 \mu \mathrm{L}$ of previously diluted anti-canine CD4 or CD8 cell surface marker mAbs, labeled with FITC (SEROTEC, Oxford, UK). Following incubation for $30 \mathrm{~min}$ at RT, protected from light, the membrane-stained samples were treated with $3 \mathrm{~mL}$ of FACS Lysing/fix Solution (BD Biosciences, San Jose, CA, USA), immediately vortexed and re-incubated for $10 \mathrm{~min}$ at room temperature. The membrane-stained lymphocytes were then permeabilized by incubation for $15 \mathrm{~min}$ with $3 \mathrm{~mL}$ of FACS perm-buffer (FACS buffer supplemented with $0.5 \%$ of saponin). The cells were incubated for $30 \mathrm{~min}$ at $\mathrm{RT}$, protected from light in the presence of $50 \mu \mathrm{L}$ of previously diluted anti-IFN- $\gamma$ or IL-4 mAbs, labeled with PE (SEROTEC, Oxford, UK). After intracellular staining, the cells were washed once with FACS perm-buffer, followed by one washing step with FACS buffer and finally fixed in FACS FIX Solution. FITC and PE-labeled isotypic controls were included in each batch of experiments. Flow cytometric measurements were performed on a FACScan instrument (Becton Dickinson, Moutain View, CA) interfaced to an apple G3 FACStation. The Cell-Quest ${ }^{\mathrm{TM}}$ software package provided by the manufacturer (Franklin Lakes, NJ, USA) was used for data acquisition and analysis. A total of 30,000 events were acquired for each preparation. The analysis of the cytokine profile of $\mathrm{CD}^{+}$and $\mathrm{CD}^{+}$T-cell subsets was performed by first establishing a scattering gate on the lymphocyte population, using laser forward scatter (FSC) versus laser side scatter (SSC) dot plot distributions, followed by quantification of cytokine expressing cells on FL1/FITC versus FL2/PE dot plots combinations. The cytokine $^{+}$T-cell subsets were identified into the upperright quadrant on dual color graphs with the FL1/FITC axis representing immunostaining with the anti-cell surface marker FITC-labeled mAb (CD4 or CD8) and FL2/PE corresponding to the immunostaining with the anti-cytokine PE-labeled $\mathrm{mAb}$ (IFN- $\gamma$ or IL-4). The results were expressed as the percentage of double labeled cells (IFN- $\gamma^{+} \mathrm{CD} 4^{+}$, $\mathrm{IL}-4^{+} \mathrm{CD} 4^{+}, \mathrm{IFN}-\gamma^{+} \mathrm{CD} 8^{+}$and IL- $4^{+} \mathrm{CD} 8^{+}$) within the lymphocyte logical gate.

\subsection{Nitric oxide (NO) synthesis analysis}

The concentration of nitrite $\left(\mathrm{NO}_{2}{ }^{-}\right)$released in the supernatant of in vitro PBMC cultures was measured using the Griess reaction (Green et al., 1992). Briefly, a $100 \mu \mathrm{L}$ aliquot of cell-free culture supernatant was mixed with $100 \mu \mathrm{L}$ of Griess reagent (1\% sulphanylamide, $0.1 \%$ naphthylethylene-diamide-dihydrochloride and $2.5 \%$ phosphoric acid, all from Sigma, St Louis, MO, USA). Following $10 \mathrm{~min}$ of incubation at RT, protected from light, the absorbance was measured at $540 \mathrm{~nm}$, using a microplate reader. Each sample was assayed in duplicate and the concentration of nitrite was determined by interpolation from a standard curve constructed using sodium nitrite solutions of known concentration in the range $0-100 \mu \mathrm{M}$. To discount the interference of nitrites already present in the culture medium, data were calculated taking into account the blank for each experiment, assayed by using the medium employed for the in vitro PBMC cultures. Considering the wide variation in the percentage of monocytes 
Table 1

Phenotypic features and activation status of innate immunity cells in the peripheral blood of German Shepherd dogs following Leishvaccine and Leishmune ${ }^{\circledR}$ vaccination regimens*.

\begin{tabular}{|c|c|c|c|c|c|c|c|c|}
\hline \multirow[t]{3}{*}{ Cell phenotypes } & \multicolumn{8}{|c|}{ Immunobiological tool } \\
\hline & \multicolumn{4}{|l|}{ Leishvaccine } & \multicolumn{4}{|l|}{ Leishmune $^{\circledR}$} \\
\hline & T0 & $\mathrm{T} 1$ & $\mathrm{~T} 2$ & T3 & T0 & $\mathrm{T} 1$ & $\mathrm{~T} 2$ & T3 \\
\hline \multicolumn{9}{|l|}{ Neutrophils } \\
\hline $\mathrm{MHCII}^{+}$ & $0.5 \pm 0.2$ & $\uparrow 1.9 \pm 0.7$ & $\uparrow 3.8 \pm 1.6$ & $\uparrow 2.1 \pm 0.4$ & $0.8 \pm 0.4$ & $\uparrow 1.6 \pm 0.3$ & $\uparrow 3.4 \pm 0.7$ & $\uparrow 1.8 \pm 0.5$ \\
\hline $\mathrm{CD}_{3} 2^{+}$ & $1.7 \pm 1.7$ & $\downarrow 0.4 \pm 0.4$ & $\downarrow 0.4 \pm 0.2$ & $\downarrow 0.6 \pm 0.7$ & $1.3 \pm 0.8$ & $\downarrow 0.5 \pm 0.4$ & $\downarrow 0.3 \pm 0.2$ & $\downarrow 0.3 \pm 0.3$ \\
\hline CD18 ${ }^{+}$ & $78.7 \pm 26.5$ & $\downarrow 53.8 \pm 20.4$ & $\downarrow 41.9 \pm 7.6$ & $\downarrow 35.3 \pm 9.3$ & $76.7 \pm 30.0$ & $\downarrow 47.1 \pm 11.1$ & $\downarrow 42.3 \pm 11.2$ & $\downarrow 35.4 \pm 8.2$ \\
\hline \multicolumn{9}{|l|}{ Eosinophils } \\
\hline $\mathrm{MHCII}^{+}$ & $0.6 \pm 0.8$ & $0.4 \pm 0.7$ & $0.3 \pm 0.3$ & $0.4 \pm 0.4$ & $0.4 \pm 0.2$ & $0.3 \pm 0.4$ & $0.3 \pm 0.1$ & $0.4 \pm 0.3$ \\
\hline $\mathrm{CD}_{3} 2^{+}$ & $2.0 \pm 2.6$ & $1.0 \pm 2.1$ & $\downarrow 0.6 \pm 0.5$ & $\downarrow 0.2 \pm 0.1$ & $2.3 \pm 5.1$ & $0.5 \pm 0.8$ & $0.6 \pm 0.5$ & $0.4 \pm 0.6$ \\
\hline $\mathrm{CD}_{18}{ }^{+}$ & $64.6 \pm 13.3$ & $\uparrow 103.8 \pm 30.3$ & $\uparrow 89.5 \pm 28.6$ & $75.2 \pm 23.9$ & $65.7 \pm 26.8$ & $82.2 \pm 26.7$ & $88.3 \pm 23.5$ & $79.6 \pm 24.5$ \\
\hline \multicolumn{9}{|l|}{ Monocytes } \\
\hline $\mathrm{MHCII}^{\mathrm{High}+}$ & $76.8 \pm 6.3$ & $77.5 \pm 8.6$ & $76.7 \pm 8.4$ & $71.8 \pm 8.9$ & $74.9 \pm 4.8$ & $76.7 \pm 5.8$ & $74.5 \pm 9.2$ & $72.7 \pm 5.7$ \\
\hline $\mathrm{CD}_{32}{ }^{+}$ & $1.7 \pm 1.1$ & $1.7 \pm 1.2$ & $0.8 \pm 0.6$ & $1.3 \pm 0.8$ & $3.5 \pm 4.9$ & $1.6 \pm 0.8$ & $1.4 \pm 1.1$ & $1.0 \pm 0.6$ \\
\hline $\mathrm{CD} 18^{+}$ & $137.5 \pm 64.3$ & $155.5 \pm 58.7$ & $169.0 \pm 44.8$ & $\uparrow 105.5 \pm 32.8$ & $139.4 \pm 57.3$ & $164.13 \pm 55.2$ & $148.2 \pm 26.3$ & $127.7 \pm 39.1$ \\
\hline
\end{tabular}

* The results are expressed as the mean percentage \pm standard deviation of positive cells within the gated cell population, except for CD18, which is reported as the average \pm standard deviation of mean fluorescence intensity of cell surface marker expression within the gated cell population. $\downarrow \uparrow$ Significant differences at $p<0.05$ as compared to T0.

(7-52\%) in the PBMC samples used to the in vitro culture assays, there was a need to establish a normalizing factor to correct the level of nitrite found in culture supernatant, which was then expressed as nitrite $(\mu M) /$ monocyte index. This index was obtained dividing a given nitrite concentration $(\mu \mathrm{M})$ by the number of monocytes added to each in vitro PBMC culture (nitrite/monocytes).

\subsection{Statistical analysis}

Statistical analysis was performed using the GraphPad Prism 4.03 software package (San Diego, CA, USA). Considering the nonparametric nature of all data sets, the Wilcoxon matched pairs test was used to access significant differences on the phenotypic features and activation status of innate and adaptive immunity cells for each immunobiological tool, throughout the experimental procedures by comparing the data from the post-vaccination timing points (T1, T2 and T3) with the starting point (T0). Analysis of intracytoplasmic cytokines and nitric oxide levels were performed by ANOVA followed by Tukey's multiple comparison test to identify differences between T0 and T4 for each immunobiological tool, as well as for comparisons between the immunobiological tools. In all cases, the differences were considered significant when the probabilities of equality, $p$-values were $<0.05$.

\section{Results and discussion}

\subsection{Impact of Leishvaccine or Leishmune ${ }^{\circledR}$ on the peripheral blood innate immunity profile}

Kinetic analysis of phenotypic changes in circulating neutrophils showed that dogs immunized with Leishvaccine displayed a persistent up regulation of MHCII as observed throughout the vaccination regimen at T1, T2 and T3, despite the immunogenic tool used (Table 1). Down regulation of CD32 parallel with lower CD18 expression was also the hallmark of the phenotypic changes on neutrophils during the entire immunization procedure (T1, T2 and T3) with either Leishvaccine or Leishmune ${ }^{\circledR}$ (Table 1). These data demonstrated that both immunobiological tools triggered an overall similar phenotypic change on circulating neutrophils following the vaccination regimen.

Kinetic analysis of phenotypic changes in circulating eosinophils demonstrated that dogs immunized with Leishvaccine display changes in eosinophil phenotypic features, with down-regulation of CD32 expression at T2 and T3 (Table 1). Moreover, up-regulation of CD18 expression was observed at $\mathrm{T} 1$ and $\mathrm{T} 2$ (Table 1 ). No significant differences were observed in the percentage of $\mathrm{MHCII}^{+}$ eosinophils throughout the vaccination regimen, regardless the immunobiological tool (Table 1). Dogs vaccinated with Leishmune ${ }^{\circledR}$ did not show any phenotypic changes in eosinophils throughout the immunization regimen.

No significant difference was observed in the expression of MHCII by circulating monocytes as well as in the percentage of $\mathrm{CD}_{3} 2^{+}$monocytes in the vaccination regimens (Table 1 ). Punctual down-regulation monocytes CD18 expression was observed at T3 following the immunization with Leishvaccine (Table 1 ).

Together, our findings demonstrated that interventions with Leishvaccine or Leishmune ${ }^{\circledR}$ generated a distinct immunephenotypic changes in the innate immune response profile. Leishvaccine promoted an early phenotypic changes in neutrophils (MHCII, CD18 and CD32) and eosinophils (CD32 and CD18), with late monocytes involvement (CD18). On the other hand, Leishmune ${ }^{\circledR}$ induced an early and persistent phenotypic changes in neutrophils (MHCII, CD18 and CD32) with no alteration in eosinophils (Fig. 2 - left diagram).

The activation of neutrophils and macrophages, relevant targets of Leishmania, represents one of the first events linked to the innate immune response to intracellular infection (Rousseau et al., 2001). Upon their activation, neutrophils and monocytes are recruited to inflammatory foci where secrete type 1 cytokines, and play a role to drive the adaptive immune compartment toward a 


\section{Immunophenotypic features - cell surface markers}

\section{Innate Immunity}
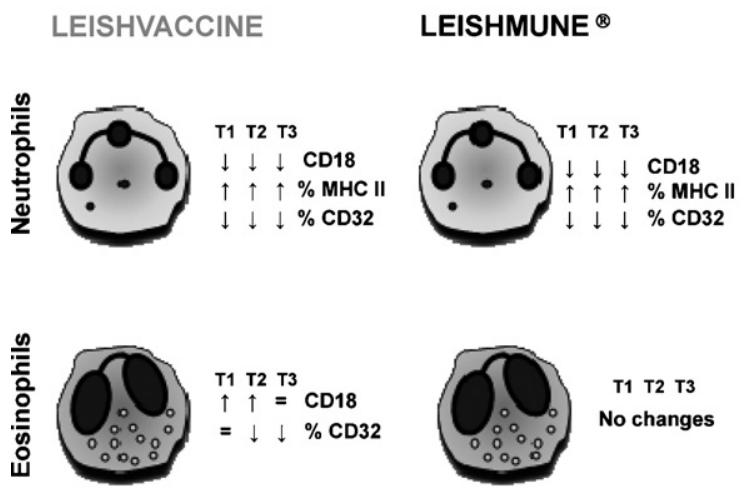

T1 T2 T3 No changes
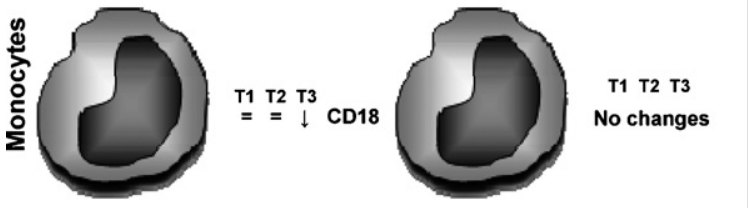

LEISHVACCINE
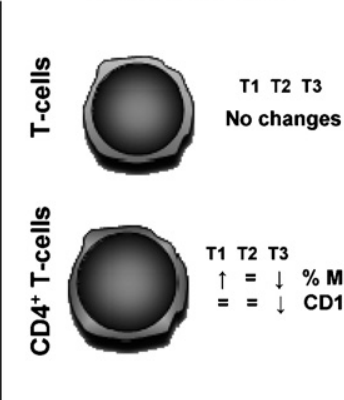

T1 T2 T3

$\uparrow=\downarrow \%$ MHC I

$==\downarrow \mathrm{CD} 18$

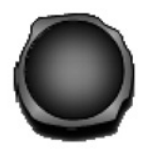

$\stackrel{\mathrm{T} 1}{=} \stackrel{\mathrm{T} 2}{=} \mathrm{I}^{3}$

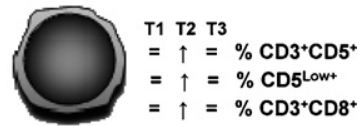

LEISHMUNE ${ }^{\oplus}$
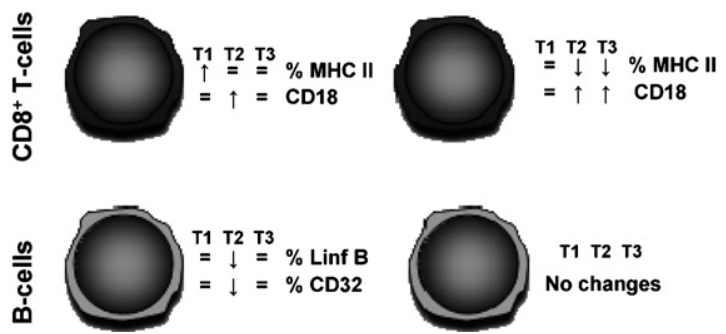

Fig. 2. Major immunophenotypic features observed at T1, T2 and T3 for each cell surface marker. The symbols (=, $\uparrow$ and $\downarrow$ ) refer to basal, increased or decreased levels, respectively and illustrate the statistical analysis as compared to unvaccinated dogs.

cellular response, necessary in parasite clearance (Vouldoukis et al., 1997; McFarlane et al., 2008). This microenvironment up-regulate the anti-Leishmania activity, increasing the phagocytosis and parasite killing through mechanisms such as those related to oxidative burst (Vouldoukis et al., 1997). Rousseau et al. (2001) showed that during the early phase of the infection, neutrophils are relevant in controlling $L$. infantum burden in the spleen. Furthermore, in $L$. donovani-infected mice, the depletion of the neutrophils induced a significant enhancement of parasite growth in both liver and spleen (McFarlane et al., 2008). Indeed, these data associated with our results reinforce the hypothesis that the involvement of the innate immune response, elicited by both vaccines, could be crucial in the development of the protective immune response during Leishmania challenge. Furthermore, it is relevant point out that the adaptive cell memory following vaccination is necessary to vaccine's success (Barbiéri, 2006). We hypothesized that the distinct antigenic nature of these immunobiological (Leishvaccine complex, crude antigen and Leishmune ${ }^{\circledR}$ purified, FML antigen) could be closely related to the distinct immunological profile observed. The recognition of antigenic epitopes and the initiation of host defense responses by the innate immunity cells are controlled by multiple mechanisms (Iwasaki and Medzhitov, 2004). Several recognition strategies have been described, as the pattern-recognition strategy that is based on the detection of a limited set of conserved molecular patterns (PAMPs) that are unique to the microbial world and invariant among entire classes of pathogens. The targets of the PAMPs are detected by pattern recognition receptors, namely toll- like receptors (TLRs). There are at least 10 mammalian TLRs expressed by different cell populations, considering innate response cells, the neutrophils express TLR1 through TLR10, except TLR3, eosinophils TLR1, TLR4, TLR7, TLR9, TLR10 and monocytes express TLR1 through TLR8, except TLR3 (Iwasaki and Medzhitov, 2004). Although the interaction between Leishmania antigens and TLR in the canine innate immune cells may resemble that already described in the mouse models and in human studies, it is plausible to believe that distinct antigen composition of Leishmune ${ }^{\circledR}$ and Leishvaccine my lead to a distinct pattern of TLR activation. In this context, in a speculative analysis, we hypothesized that the complex antigenic nature of the Leishvaccine would lead to a multiplicity of interaction with a wide range of TLRs and therefore trigger the activation of several leukocyte cell subsets within the innate immune compartment. In contrast, the FML, purified antigen from the Leishmune ${ }^{\circledR}$, may interact with TLR2 (molecule present in neutrophils and monocytes but not in eosinophils) and therefore trigger a selective stimulation of phagocytes.

Despite the distinct profile triggered by Leishmune ${ }^{\circledR}$ and Leishvaccine vaccines in the innate immunity cells, it is relevant to mention that both immunobiologicals are capable to stimulate relevant innate immunity cells involved in leshmanicidal activities, such as neutrophils and monocytes that enable them to elicit a protective immune response against Leishmania infection. This was particularly demonstrated by the analysis of cell surface markers related with cell activation and migration (MHC and CD18, respectively) demonstrated that both immunobiologicals promote a recruitment of neutrophils and monocytes. This 
Table 2

Phenotypic features and activation status of adaptive immunity cells in the peripheral blood of German Shepherd dogs following Leishvaccine and Leishmune $^{\circledR}$ vaccination regimens.

\begin{tabular}{|c|c|c|c|c|c|c|c|c|}
\hline \multirow[t]{3}{*}{ Cell phenotypes } & \multicolumn{8}{|c|}{ Immunobiological tools } \\
\hline & \multicolumn{4}{|l|}{ Leishvaccine } & \multicolumn{4}{|l|}{ Leishmune $^{\circledR}$} \\
\hline & T0 & $\mathrm{T} 1$ & $\mathrm{~T} 2$ & T3 & T0 & $\mathrm{T} 1$ & $\mathrm{~T} 2$ & T3 \\
\hline T-cells $\left(\mathrm{CD}^{+} \mathrm{CD}^{+}\right)$ & $66.3 \pm 17.9$ & $76.8 \pm 8.0$ & $78.7 \pm 7.4$ & $75.4 \pm 6.5$ & $71.5 \pm 9.7$ & $77.1 \pm 6.8$ & $\uparrow 81.0 \pm 5.2$ & $77.6 \pm 5.6$ \\
\hline B-cells & $9.3 \pm 4.4$ & $8.8 \pm 2.8$ & $\downarrow 7.3 \pm 2.6$ & $8.3 \pm 3.6$ & $9.8 \pm 3.5$ & $9.4 \pm 3.5$ & $8.1 \pm 2.2$ & $8.9 \pm 2.6$ \\
\hline $\mathrm{T} / \mathrm{B}$-cell ratio & $7.0 \pm 2.8$ & $10.5 \pm 6.7$ & $\uparrow 10.7 \pm 2.7$ & $10.3 \pm 5.2$ & $7.8 \pm 4.3$ & $11.6 \pm 11.8$ & $11.1 \pm 3.8$ & $10.3 \pm 3.1$ \\
\hline $\mathrm{CD}^{+} \mathrm{CD}^{+}$ & $34.7 \pm 6.6$ & $36.1 \pm 7.2$ & $36.8 \pm 6.0$ & $38.3 \pm 6.1$ & $38.9 \pm 7.9$ & $39.8 \pm 6.6$ & $41.1 \pm 7.8$ & $42.5 \pm 5.9$ \\
\hline $\mathrm{CD}^{+} \mathrm{CD}^{+}$ & $31.2 \pm 8.2$ & $31.8 \pm 10.0$ & $35.1 \pm 11.2$ & $32.3 \pm 10.8$ & $26.7 \pm 5.2$ & $28.2 \pm 3.8$ & $\uparrow 31.6 \pm 4.5$ & $28.5 \pm 3.9$ \\
\hline $\mathrm{CD}^{+} \mathrm{CD}^{\mathrm{Low}+}$ & $22.6 \pm 9.4$ & $27.5 \pm 10.7$ & $28.2 \pm 12.3$ & $24.8 \pm 12.5$ & $21.8 \pm 6.2$ & $23.7 \pm 4.8$ & $\uparrow 27.1 \pm 7.4$ & $23.6 \pm 5.6$ \\
\hline $\mathrm{CD}^{+} / \mathrm{CD}^{+}$ratio & $1.2 \pm 0.6$ & $1.3 \pm 0.5$ & $1.1 \pm 0.4$ & $1.5 \pm 0.6$ & $1.5 \pm 0.5$ & $1.4 \pm 0.3$ & $1.3 \pm 0.4$ & $1.5 \pm 0.3$ \\
\hline $\mathrm{CD} 4^{+} \mathrm{CD} 18^{+*}$ & $1.5 \pm 2.3$ & $1.1 \pm 0.9$ & $0.6 \pm 0.4$ & $\uparrow 1.9 \pm 1.1$ & $1.1 \pm 1.0$ & $0.6 \pm 0.3$ & $1.0 \pm 0.7$ & $1.1 \pm 0.9$ \\
\hline $\mathrm{CD}^{+} \mathrm{MHCII}^{+}$ & $45.5 \pm 8.9$ & $\uparrow 64.9 \pm 27.8$ & $44.3 \pm 10.0$ & $\downarrow 35.5 \pm 9.8$ & $48.7 \pm 10.9$ & $57.8 \pm 21.8$ & $46.8 \pm 9.2$ & $\downarrow 36.5 \pm 10.7$ \\
\hline $\mathrm{CD}^{+} \mathrm{CD} 18^{+}$ & $0.5 \pm 1.7$ & $1.0 \pm 0.7$ & $\uparrow 14.4 \pm 7.9$ & $3.9 \pm 1.9$ & $0.3 \pm 0.4$ & $0.48 \pm 0.3$ & $\uparrow 10.4 \pm 7.7$ & $\uparrow 3.9 \pm 2.7$ \\
\hline $\mathrm{CD}^{+} \mathrm{MHCII}^{+}$ & $54.3 \pm 20.8$ & $62.6 \pm 27.5$ & $44.5 \pm 12.1$ & $\downarrow 39.1 \pm 12.7$ & $47.9 \pm 12.8$ & $52.0 \pm 18.3$ & $\downarrow 43.5 \pm 11.1$ & $\downarrow 41.7 \pm 15.2$ \\
\hline $\mathrm{CD}_{2} 2^{+} \mathrm{B}$-cells & $8.6 \pm 9.9$ & $5.8 \pm 6.1$ & $\downarrow 1.9 \pm 2.9$ & $3.4 \pm 2.7$ & $5.8 \pm 8.9$ & $3.4 \pm 2.8$ & $2.2 \pm 2.0$ & $2.6 \pm 2.0$ \\
\hline
\end{tabular}

* The results are expressed as the mean percentage \pm standard deviation of positive cells within the gated cell population, except for MHCII, which is reported as the average \pm standard deviation of mean fluorescence intensity of cell surface marker expression within the gated cell population. $\downarrow \uparrow$ Significant differences at $p<0.05$ as compared to T0.

ability suggests their capacity to induce immunoprotective mechanisms regarding CVL immunoprophylaxis.

\subsection{Impact of Leishvaccine or Leishmune ${ }^{\circledR}$ on the peripheral blood adaptive immunity profile}

Kinetic analysis of phenotypic changes in major subpopulations of circulating lymphocytes demonstrated an up-regulation of T-cells with parallel increase on circulating $\mathrm{CD}^{+} \mathrm{T}$-cells were the outstanding phenotypic feature at T2 following Leishmune ${ }^{\circledR}$ vaccination (Table 2 ). Moreover, a selective up-regulation of $\mathrm{CD}^{+} \mathrm{CD}^{\mathrm{Low}+} \mathrm{T}$-cells was observed particularly at $\mathrm{T} 2$ following Leishmune ${ }^{\circledR}$ vaccination (Table 2). Additional analysis has further addressed the positive correlation between $\mathrm{CD}^{+} \mathrm{CD}^{\mathrm{Low}+} \mathrm{T}$-cells and the percentage of circulating $\mathrm{CD}^{+} \mathrm{T}$-cells following Leishmune ${ }^{\circledR}$ vaccination (data not shown). On the one hand, down-regulation of B-cells with consecutive upregulation of $\mathrm{T} / \mathrm{B}$ cell ratio was observed at $\mathrm{T} 2$ following Leishvaccine immunization (Table 2).

Additional analysis of T-lymphocyte subsets revealed that changes in $\mathrm{CD}_{18}{ }^{+} \mathrm{CD} 4^{+}$T-cells at $\mathrm{T} 3$ and $\mathrm{MHCII}$ expression by $\mathrm{CD} 4^{+} \mathrm{T}$-cells at $\mathrm{T} 1$ and $\mathrm{T} 3$ with transient up-regulation of $\mathrm{CD}_{18}{ }^{+} \mathrm{CD}^{+}$T-cells at $\mathrm{T} 2$ and $\mathrm{MHCII}$ expression by $\mathrm{CD}^{+} \mathrm{T}$-cells at $\mathrm{T} 3$, are the hallmark of Leishvaccine immunization (Table 2). On the other hand, Leishmune ${ }^{\circledR}$ vaccination was associated with a transient down-regulation of $\mathrm{MHCII}^{+} \mathrm{CD}^{+} \mathrm{T}$-cells at $\mathrm{T} 3$ and a persistent up-regulation of $\mathrm{CD} 18^{+} \mathrm{CD}^{+} \mathrm{T}$-cells and decreased expression of MHCII by $\mathrm{CD}^{+} \mathrm{T}$-cells at $\mathrm{T} 2$ and T3. Downregulation of CD32 expression on B-cells was observed at T2, selectively in dogs immunized with Leishvaccine, whereas no changes were observed in dogs vaccinated with Leishmune ${ }^{\circledR}$ (Table 2).

Together, our findings regarding the immunophenotypic features of circulating leukocytes summarized in Fig. 2, demonstrated that the vaccine interventions (Leish- vaccine and Leishmune ${ }^{\circledR}$ ) also triggered distinct changes in the adaptive immunity cells. In fact, whereas Leishvaccine promoted a mixed immune response, associated with early changes on $\mathrm{CD}^{+}{ }^{+} \mathrm{T}$-cells (MHCII), followed by B-lymphocytes (CD32) and later changes in $\mathrm{CD}^{+} \mathrm{T}$-cells (MHCII and CD18), the Leishmune ${ }^{\circledR}$ promoted a distinct immune response, associated with late changes on $\mathrm{CD}^{+} \mathrm{T}$ cells (MHCII) and persistent changes on $\mathrm{CD}^{+}$(MHCII and CD18) (Fig. 2 - right diagram). It is relevant to mention that although the immunobiologicals triggered distinct phenotypic changes in the adaptive immunity cells, both were capable to induce changes on $\mathrm{CD}^{+} \mathrm{T}$-cells that are considered to be the major element in the protective mechanisms for CVL immunoprophylaxis. The ability of Leishvaccine to induce a mixed pattern of immune response with parallel involvement of $\mathrm{CD}^{+} \mathrm{T}$-cells and B-lymphocytes further support our hypothesis that the complex antigenic constitution of this immunobiologic characterized by the whole L. amazonensis crude antigen is probably the main element underlying the broader immunogenic profile of Leishvaccine. We believe that the preferential activation of T-cells by Leishmune ${ }^{\circledR}$, specially $\mathrm{CD}^{+}$T-cells and $\mathrm{CD}^{+} \mathrm{CD}^{\mathrm{Low}}{ }^{+}$ cells is mostly related to the purified nature of the antigen constituent of the Leishmune ${ }^{\circledR}$. We supposed that saponin adjuvant facilitates FML transference into intracellular compartments and therefore it could be processed and presented by antigen presenting cells using the $\mathrm{MHCI}$ pathway. Moreover, another possibility is that CD8 ${ }^{+} \mathrm{T}$-cells may be activated by foreign antigens throughout a "crosspriming” mechanism, since APCs (antigen presenting cells), especially dendritic cells, can internalize foreign antigens and present them to $\mathrm{CD}^{+}{ }^{+} \mathrm{T}$-cells (Brossart and Bevan, 1997). It was also demonstrated that even inside the phagosome, exogenous antigens can be presented to $\mathrm{CD} 8^{+} \mathrm{T}$-cells by MHCI molecules expressed by professional APCs (Houde et al., 2003). It is relevant to point out the relevance that has been given to the role of $\mathrm{CD}^{+} \mathrm{T}$-cells in CVL. Many stud- 
ies have showed the $\mathrm{CD}^{+} \mathrm{T}$-cells recruitment importance in protection against CVL (Barbiéri, 2006). As presented by Pinelli et al. (1994) the CD8 ${ }^{+} \mathrm{T}$-cells play a pivotal role in the protective immunity during the infection with $L$. infantum. These authors have observed that $\mathrm{CD} 8^{+} \mathrm{T}$-cells are not only capable to generate a potent immune response mediated by the secretion of IFN- $\gamma$ but also are effective to lysate $L$. infantum infected macrophages. Moreover, Pinelli et al. (1994) have also evidenced the dependence of $\mathrm{CD}^{+}$ $\mathrm{T}$-cells effectiveness with the activity of $\mathrm{CD} 4^{+} \mathrm{T}$-cells. In fact, some studies have demonstrated that the cytokines microenvironment created by $\mathrm{CD} 4^{+} \mathrm{T}$-cells play a role to direct the immune response in the cellular and humoral immunity pathways (Vouldoukis et al., 1997; Kemp et al., 1999; Barbiéri, 2006).

\subsection{Impact of Leishvaccine and Leishmune ${ }^{\circledR}$ in the cytokine profile and nitric oxide synthesis by peripheral blood mononuclear cells}

Aiming to focus on the impact of Leishvaccine and Leishmune ${ }^{\circledR}$ vaccines on the T-cell cytokine pattern, we have characterized the frequency of cytokine-producing cells (IFN- $\gamma^{+}$and $\mathrm{IL}-4^{+}$) within the T-cell subsets (CD4 ${ }^{+}$ and $\mathrm{CD}^{+}$) following in vitro cultures of peripheral blood mononuclear cells (PBMC) collected from unvaccinated as well as Leishvaccine and Leishmune ${ }^{\circledR}$ vaccinated dogs. The cultures were performed in the absence (Control-CC) or presence of soluble L. chagasi antigens (SLA).

Our data demonstrated that both Leishvaccine and Leishmune ${ }^{\circledR}$ induced increased levels of IFN- $\gamma^{+}$T-cells as compared with unvaccinated dogs, in both CC and SLA cultures (Table 3). This phenomenon was selectively observed in $\mathrm{CD}^{+} \mathrm{T}$-cells with no changes in the frequency of IFN$\gamma^{+} \mathrm{CD}^{+} \mathrm{T}$-cells (Table 3 ). It was interesting to notice that Leishmune ${ }^{\circledR}$ showed no significant levels of IL- 4 .

Increased percentages of $\mathrm{IL}_{-} 4^{+} \mathrm{CD} 4^{+}$T-cells were observed in the CC culture of PBMC from Leishvaccine immunized dogs compared to unvaccinated controls (Table 3). Moreover, higher levels of IL- $4^{+}$T-cells (specifically $\mathrm{CD}^{+} \mathrm{T}$-cells) were observed in the SLA cultures of PBMC from Leishvaccine immunized dogs as compared to unvaccinated dogs as well as with Leishmune ${ }^{\circledR}$ vaccinated animals (Table 3 ).

Increased IFN $-\gamma^{+} / \mathrm{IL}-4^{+}$T-cells ratio was selectively observed in the SLA cultures of PBMC isolated from Leishmune ${ }^{\circledR}$ vaccinated dogs. Interestingly, this increased IFN- $\gamma^{+} /$IL- $4^{+}$T-cells ratio was also higher as compared to that observed in the CC culture of PBMC obtained from these animals. As previously mentioned, the distinct profiles of immune response elicited during vaccination with Leishvaccine and Leishmune ${ }^{\circledR}$ could be associated with vaccines antigenic molecular nature. Therefore, the multiplicity of interactions induced by Leishvaccine, consistent with the complex nature antigen of L. amazonensis used as the immunogenic basis of this vaccine, would be the basis for the mixed cytokine profile observed in the PBMC cultures. On the other hand, the single nature of the purified antigen, used in Leishmune ${ }^{\circledR}$ vaccine, corroborates with its selective profile in the activation of PBMCs and the selective cytokine network observed.

It has been demonstrated that the cellular immune responses mediated by IFN- $\gamma$ and TNF- $\alpha$ are predominant in asymptomatic dogs and therefore it has been pointed out as an apparent biomarker of resistance in visceral leishmaniasis (Barbiéri, 2006). On the other hand, there are increasing evidences that regulatory cytokines, such as IL4 , may be associated with progressive disease in Leishmania infected dogs (Barbiéri, 2006). Interestingly, even though IL-4 expression was not previously found to be significantly elevated in the bone marrow of $L$. infantum infected dogs, higher expression was associated with the presence of more severe clinical signs (Quinnell et al., 2001). Moreover, IL-4 expression in skin biopsies obtained from Leishmania infected dogs was found to be significantly higher than in similar samples taken from uninfected dogs and was correlated with increased parasite load in skin lesions (Brachelente et al., 2005). Therefore, we believe that the IL4 triggered by the Leishvaccine could represent a drawback phenomenon that could impact the macrophage activation and somehow the parasite survival and replication. Studies of first generation vaccines, prepared with Leishamania crude antigens, combined with a range of distinct adjuvant combinations are currently under investigation

Table 3

Cytokines and nitric oxide synthesis in vitro by peripheral blood mononuclear cells from German Shepherd dogs following Leishvaccine and Leishmune ${ }^{\circledR}$ vaccination regimens.

\begin{tabular}{|c|c|c|c|c|c|c|}
\hline \multirow[t]{3}{*}{ Parameters } & \multicolumn{6}{|c|}{ Immunobiological tools } \\
\hline & \multicolumn{2}{|l|}{ (T0) } & \multicolumn{2}{|c|}{ Leishvaccine (T4) } & \multicolumn{2}{|c|}{ Leishmune $^{\circledR}$ (T4) } \\
\hline & $\mathrm{CC}$ & SLA & $\mathrm{CC}$ & SLA & $\mathrm{CC}$ & SLA \\
\hline INF- $\gamma^{+} \mathrm{T}$-cells & $0.6 \pm 0.1$ & $0.6 \pm 0.1$ & $\uparrow 1.3 \pm 0.2$ & $\uparrow 1.4 \pm 0.3$ & $\uparrow 1.1 \pm 0.1$ & $\uparrow 1.2 \pm 0.2$ \\
\hline IL- $4^{+} \mathrm{T}$-cells & $1.1 \pm 0.3$ & $0.9 \pm 0.1$ & $1.4 \pm 0.0$ & $\uparrow^{*} 2.1 \pm 0.5$ & $1.1 \pm 0.2$ & $1.0 \pm 0.1$ \\
\hline INF- $\gamma^{+} /$IL- $4^{+}$T-cell ratio & $0.5 \pm 0.1$ & $0.7 \pm 0.1$ & $\uparrow 0.9 \pm 0.1$ & $0.9 \pm 0.2$ & $\uparrow 1.0 \pm 0.0$ & $\uparrow^{\#} 1.4 \pm 0.2$ \\
\hline INF- $\gamma^{+}$CD $4^{+}$cells & $0.3 \pm 0.1$ & $0.4 \pm 0.1$ & $\uparrow 0.7 \pm 0.1$ & $\uparrow 1.4 \pm 0.6$ & $\uparrow 0.7 \pm 0.1$ & $\uparrow 0.8 \pm 0.2$ \\
\hline IL- $4^{+}$CD $4^{+}$cells & $0.5 \pm 0.1$ & $0.5 \pm 0.1$ & $\uparrow 0.8 \pm 0.1$ & $0.7 \pm 0.2$ & $0.7 \pm 0.1$ & $0.6 \pm 0.0$ \\
\hline INF- $\gamma^{+}$CD $8^{+}$cells & $0.3 \pm 0.1$ & $0.3 \pm 0.1$ & $0.4 \pm 0.1$ & $0.5 \pm 0.1$ & $0.4 \pm 0.0$ & $0.4 \pm 0.1$ \\
\hline IL- $4^{+}$CD $8^{+}$cells & $0.4 \pm 0.1$ & $0.3 \pm 0.1$ & $0.5 \pm 0.1$ & $\uparrow 1.0 \pm 0.3$ & $0.4 \pm 0.1$ & $0.4 \pm 0.1$ \\
\hline NO/monocytes $\left(\times 10^{-5}\right)$ & $0.5 \pm 0.1$ & $0.6 \pm 0.1$ & $1.0 \pm 0.2$ & $1.2 \pm 0.3$ & $\uparrow^{*} 2.0 \pm 0.4$ & $\uparrow 1.6 \pm 0.3$ \\
\hline
\end{tabular}

* The results are expressed as the mean percentage \pm standard deviation of positive cells within gated lymphocytes after in vitro incubation in the absence (CC) or presence of Leishmania chagasi soluble antigens (SLA), except for NO, which is reported as the mean nitrite concentration ( $\mu \mathrm{M}$ )/monocytes \pm standard deviation in the supernatant of CC and SLA stimulated cultures. $\uparrow$ Significant increase at $p<0.05$ as compared to T0. *Significant increase at $p<0.05$ as compared to the other immunobiological tool. "Significant differences at $p<0.05$ between SLA and CC. 
by our group in order to evaluate whether the IL-4 induced immune response would be avoided by specific adjuvant (Giunchetti et al., 2007, 2008a,b). In fact, adjuvants are effective to orientate distinct patterns of immune response triggered during vaccination intervention (Aucouturier et al., 2001). In this context, the formalin-killed Bacille Calmette-Guérin (BCG), adjuvant used in Leishvaccine, has been demonstrated to play a role in the activation cellular immune response and up-regulate both type 1 and type 2 cytokines secretion (Lalor et al., 2010; Xing and Charters, 2007). In our work we believe that the BCG associated with the complex antigen of $L$. amazonensis used in Leishvaccine could help the establishment of a mixed response, with changes in cells activation markers of innate and adaptive cellular immunity. Additionally, the saponin, adjuvants used in Leishmune ${ }^{\circledR}$, induces a strong cytotoxic $\mathrm{CD}^{+} \mathrm{T}$ cells response, associated with a type 1 modulate cytokine profile 1 (Scott et al., 1985; Kensil, 1996; Rajput et al., 2007). These data are in agreement with our results that showed a preferentially involvement of $\mathrm{CD}^{+} \mathrm{T}$-cells in dogs tested with Leishmune ${ }^{\circledR}$.

Despite the particularities in the cytokine synthesis triggered by Leishvaccine and Leishmune ${ }^{\circledR}$, it was relevant to notice that the analysis of the cytokine balance demonstrated that increased IFN $-\gamma^{+} / \mathrm{IL}-4^{+}$T-cells ratio could be observed in the CC cultures of PBMC isolated from all vaccinated dogs, regardless the immunobiological used (Table 3). Together, our data on the functional features regarding the cytokine mosaic, summarized in Fig. 3, illustrated that the Leishvaccine immunization conducted to a mixed profile (may referred as Th1/Th2) with the increase of IFN- $\gamma$ and IL-4 production (Fig. 3 - left diagram), while Leishmune ${ }^{\circledR}$ immunization leaded to a unique profile (may referred as Th1) with the increase of IFN- $\gamma$ expression and consequently the increase of T-lymphocytes IFN- $\gamma^{+} /$IL$4^{+}$ratio (Fig. 3 - right diagram). Together, our cytokine findings highlighted that both immunobiologicals display potential applicability to drive type- 1 cytokine profile, presumably protective against CVL.

It has been suggested that the IFN- $\gamma$-induced nitric oxide (NO) pathway mediated by monocytes/macrophages is one of the major effector mechanism involved in the protective immune response in dogs infected with Leishmania (Panaro et al., 2001). Thus, we have analyzed the nitrite levels in the supernatants of PBMC cultures (i.e. considering the peripheral blood monocytes as the

\section{Functional features - Cytokines and Nitric Oxide Innate Immunity}

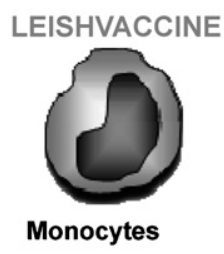

LEISHVACCINE
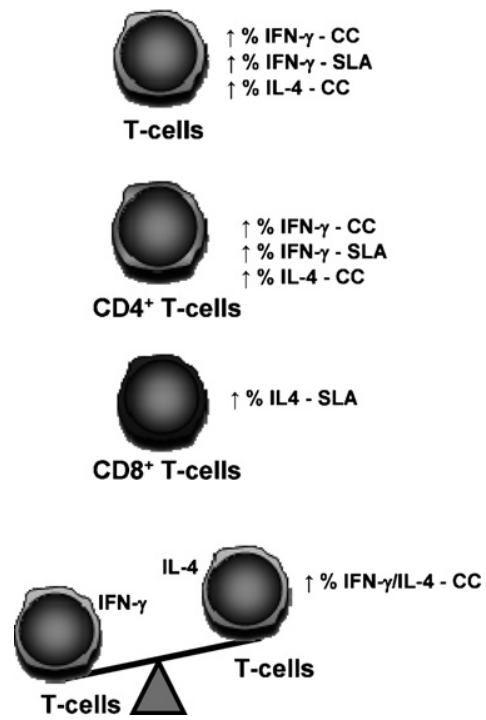

LEISHMUNE ${ }^{\circledR}$

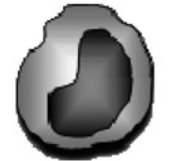

$\uparrow$ NO / Mø - CC

$\uparrow$ NO / Mø - SLA

Monocytes

Adaptive Immunity
LEISHMUNE ${ }^{\circledR}$

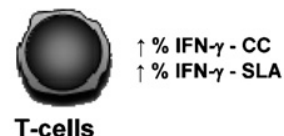

T-cells

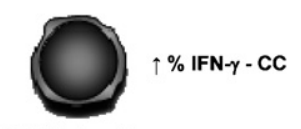

CD4 ${ }^{+}$T-cells

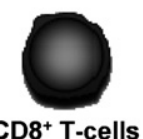

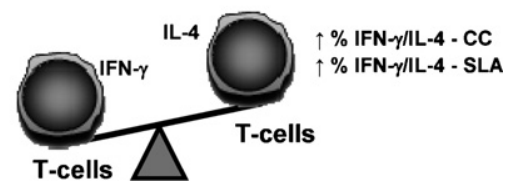

Fig. 3. Major changes in functional features of peripheral blood mononuclear cells following in vitro culture in the absence (control -CC) or the presence of soluble L. chagasi antigen (stimulated-SLA) cultures. The symbol ( $\uparrow$ ) refers to increased levels and illustrates the statistical analysis as compared to unvaccinated dogs. 
major source) to estimate the NO production by circulating monocytes (NO/Monocyte index). The results revealed that Leishmune ${ }^{\circledR}$ vaccinated dogs displayed in the $\mathrm{CC}$ cultures, higher NO/Monocyte index as compared to unvaccinated and Leishvaccine immunized dogs. In the SLA cultures, the NO/Monocyte index from Leishmune ${ }^{\circledR}$ vaccinated was selectively higher as compared to unvaccinated dogs (Table 3; Fig. 3). These findings re-emphasize that Leishmune ${ }^{\circledR}$ has the ability to activate phagocytes and support its high-quality immunogenic potential against CVL. On the other hand, the impaired NO production by circulating monocytes in Leishvaccine immunized dogs could be explained by the high levels of IL- $4^{+} \mathrm{T}$-cells.

\section{Conclusion}

Then based on our data we can conclude that a distinct immunological profiles were elicited by Leishvaccine and Leishmune ${ }^{\circledR}$, with the first inducing a mixed cytokine pattern with increased levels of IFN- $\gamma$ and IL-4, whereas the second induced an immunological pattern characterized by enhanced levels of IFN- $\gamma$ and NO. Furthermore, it should be emphasized that both immunobiologicals are able to activate phagocytes and $\mathrm{CD}^{+} \mathrm{T}$-cells and therefore could be considered priority vaccines with a high-quality immunogenic potential against CVL. These findings support further investigations focusing on perspectives of antigenic composition rational improvement as well as the adjuvant nature used for these vaccines formulation that might impact their immunoprophylactic effectiveness in the management of CVL.

\section{Acknowledgments}

The authors would like to thank the members of the Laboratório de Biomarcadores de Diagnóstico e Monitoração at Centro de Pesquisas René Rachou, FIOCRUZ-MG for providing invaluable technical assistance during this study. We are thankful to the Polícia Militar de Minas Gerais for their support with the dog management. This work was supported by CPqRR/FIOCRUZ-MG, PAPES V - FIOCRUZ (APQ 403540/2008-9) and FAPEMIG grant\# PPM0044209. O.A.M.F., W.M., A.B.R., M.N.M. and A.T.C. are grateful to Conselho Nacional de Desenvolvimento Científico e Tecnológico - CNPq and MCA to FAPEMIG for the PQ fellowships. The authors would also like to thank the program for technological development in tools for health - PDTIS FIOCRUZ for use of the flow cytometry facilities.

\section{References}

Abranches, P., Silva-Pereira, M.C., Conceição-Silva, F.M., Santos-Gomes, G.M., Janz, J.G., 1991. Canine leishmaniasis: pathological and ecological factors influencing transmission of infection. J. Parasitol. 77 (4), 557-561.

Aguilar-Torrentera, F., Carlier, Y., 2001. Immunological factors governing resistance and susceptibility of mice to Leishmania major infection. Rev. Latinoam Microbiol. 43 (3), 135-142.

Aucouturier, J., Dupuis, L., Ganne, V., 2001. Adjuvants designed for veterinary and human vaccines. Vaccine 21 (19 (17-19)), 2666-2672.

Baneth, G., Shaw, E., 2002. Chemotherapy of canine leishmanioses. Vet. Parasitol. 106, 315-324.

Barbiéri, C.L., 2006. Immunology of canine leishmaniasis. Parasite Immunol. 28 (7), 329-337.
Borja-Cabrera, G.P., Cruz Mendes, A., Paraguai de Souza, E., Hashimoto Okada, L.Y., De ATrivellato, F.A., Kawasaki, J.K., Costa, A.C., Reis, A.B. Genaro, O., Batista, L.M., Palatnik, M., Palatnik-de-Sousa, C.B., 2004 Effective immunotherapy against canine visceral leishmaniasis with the FML-vaccine. Vaccine 2 (22 (17-18)), 2234-2243.

Brachelente, C., Muller, N., Doherr, M.G., Sattler, U., Welle, M., 2005. Cutaneous leishmaniasis in naturally infected dogs is associated with a $\mathrm{T}$ helper-2-biased immune response. Vet. Pathol. 42, 166-175.

Brossart, P., Bevan, M.J., 1997. Presentation of exogenous protein antigens on major histocompatibility complex class I molecules by dendritic cells: pathway of presentation and regulation by cytokines. Blood 90 , 1594-1599.

Barclay, A.N., Brown, M.H., Law, S.K.A., McKnight, A.J., 1997. The Leucocyte Antigen Facts Book, 2nd ed. Academic Press, 613pp.

Camargo, E.P., 1964. Growth and differentiation in Trypanosoma cruzi. I. Origin of metacyclic trypanosomes in liquid media. Rev. Inst. Med. Trop. São Paulo 6, 93-100.

Carrillo, E., Moreno, J., 2009. Cytokine profiles in canine visceral leishmaniasis. Vet. Immunol. Immunopathol. 15 (128 (1-3)), 67-70.

Cobbold, S., Metcalfe, S., 1994. Monoclonal antibodies that define canine homologues of human CD antigens: summary of the First International Canine Leukocyte Antigen Workshop (CLAW). Tissue Antigens 43 (3), 137-154.

da Costa, C.A., Afonso, L.C., Toledo, V.P., Guimaraes, T.M., Nascimento, E., Tavares, C.A., Mayrink, W., 1992. Immune responses and protection induced in mice by an industrialized vaccine against American cutaneous leishmaniasis. Parassitologia 34 (1-3), 45-51.

Dantas-Torres, F., 2006. Leishmune vaccine: the newest tool for prevention and control of canine visceral leishmaniosis and its potential as a transmission-blocking vaccine. Vet. Parasitol. 141, 1-8.

Fujiwara, R.T., Bueno, L.L., Vale, A.M., Franca-Silva, J.C., da Costa, R.T., Quetz, J.S., Machado-Coelho, G.L., Reis, A.B., Martins Filho, O.A., Genaro, O., Nascimento, E., Mayrink, W., 2005. Flow cytometric assay in peripheral blood of dogs-reference values for leukocytes from Brazilian beagles. Pol. J. Vet. Sci. 8 (1), 17-22.

Giunchetti, R.C., Corrêa-Oliveira, R., Martins-Filho, O.A., Teixeira-Carvalho, A., Roatt, B.M., de Oliveira Aguiar-Soares, R.D., de Souza, J.V., das Dores Moreira, N., Malaquias, L.C., Mota e Castro, L.L., de Lana, M., Reis, A.B., 2007. Immunogenicity of a killed Leishmania vaccine with saponin adjuvant in dogs. Vaccine 25 (44), 7674-7686.

Giunchetti, R.C., Reis, A.B., da Silveira-Lemos, D., Martins-Filho, O.A., Corrêa-Oliveira, R., Bethony, J., Vale, A.M., da Silva Quetz, J., Bueno, L.L., França-Silva, J.C., Nascimento, E., Mayrink, W., Fujiwara, R.T., 2008a. Antigenicity of a whole parasite vaccine as promising candidate against canine leishmaniasis. Res. Vet. Sci. 85 (1), 106-112.

Giunchetti, R.C., Corrêa-Oliveira, R., Martins-Filho, O.A., Teixeira-Carvalho, A., Roatt, B.M., de Oliveira Aguiar-Soares, R.D., Coura-Vital, W., de Abreu, R.T., Malaquias, L.C., Gontijo, N.F., Brodskyn, C., de Oliveira, C.I., Costa, D.J., de Lana, M., Reis, A.B., 2008b. A killed Leishmania vaccine with sand fly saliva extract and saponin adjuvant displays immunogenicity in dogs. Vaccine 26 (5), 623-638.

Gradoni, L., 2001. An update on antileishmanial vaccine candidates and prospects for a canine Leishmania vaccine. Vet. Parasitol. 100, 87-103.

Green, S.J., Wagner, D.A., Glogowski, J., Skipper, P.L., Wishnork, J.S., Gutman, S.I., Hollywood, C.A., 1992. A simple' rapid method for determining nitrates and nitrites in biological fluids. Clin. Chem. 38 (10), 2152

Houde, M., Bertholet, S., Gagnon, E., Brunet, S., Goyette, G., Laplante, A., Princiotta, M.F., Thibault, P., Sacks, D., Desjardins, M., 2003. Phagosomes are competent organelles for antigen cross-presentation. Nature 25 (425 (6956)), 402-406.

Iwasaki, A., Medzhitov, R., 2004. Toll-like receptor control of the adaptive immune responses. Nat. Immunol. 5 (10), 987-995

Kemp, K., Kemp, M., Kharazmi, A., Kurtzhals, J.A.L., Theander, T.G., 1999. Leishmania-specific T cells expressing interfern-gamma (IFN-g) and IL-10 upon activation are expanded in individuals cured of visceral leishmaniasis. Clin. Exp. Immunol. 116, 500-504.

Kensil, C.R., 1996. Saponins as vaccine adjuvants. Crit. Rev. Ther. Drug Carrier Syst. 13 (1-2), 1-55.

Lalor, M.K., Smith, S.G., Floyd, S., Gorak-Stolinska, P., Weir, R.E., Blitz, R., Branson, K., Fine, P.E., Dockrell, H.M., 2010. Complex cytokine profiles induced by BCG vaccination in UK infants. Vaccine 10 (28 (6)) 1635-1641.

Lowry, O.H., Rosebrough, N.J., Farr, A.L., Randall, R.J., 1951. Protein measurement with the Folin phenol reagent. J. Biol. Chem. 193, 265-275.

Mayrink, W., Genaro, O., França-Silva, J.C., Da Costa, R.T., Tafuri, W.L., Rotondo, A., Reis, A.B., Williams, P., Costa, C.A., 1996. Phase I and II open clinical trials of a vaccine against Leishmania chagasi infections in dogs. Mem. Inst. Oswaldo Cruz. 80 (6), 695-697. 
Mayrink, W., Santos, G.C., Toledo, V., de, P., Guimaraes, T.M., MachadoCoelho, G.L., Genaro, O., da Costa, C.A., 2002. Vaccination of C57BL/10 mice against cutaneous Leishmaniasis using killed promastigotes of different strains and species of Leishmania. Rev. Soc. Bras. Med. Trop. 35 (2), 125-132.

McFarlane, E., Perez, C., Charmoy, M., Allenbach, C., Carter, K.C., Alexander, J., Tacchini-Cottier, F., 2008. Neutrophils contribute to development of a protective immune response during onset of infection with Leishmania donovani. Infect. Immun. 76 (2), 532-541.

Moore, P.F., Rossitto, P.V., Danilenko, D.M., Wielenga, J.J., Raff, R.F., Severns, E., 1992. Monoclonal antibodies specific for canine CD4 and CD8 define functional T-lymphocyte subsets and high-density expression of CD4 by canine neutrophils. Tissue Antigens 40 (2), 75-85.

Moreno, J., Alvar, J., 2002. Canine leishmaniasis: epidemiological risk and the experimental model. Trends Parasitol. 18 (9), 399-405.

Noli, C., Auxilia, S.T., 2005. Treatment of canine Old World visceral leishmaniasis: a systematic review. Vet. Dermatol. 16, 213-232.

Palatnik de Sousa, C.B., Santos, W.R., França-Silva, J.C., Costa, R.T., Reis, A.B., Palatnick, M., Mayrink, W., Genaro, O., 2001. Impact of canine control in the epidemiology of canine and human visceral leishmaniasis in Brazil. Am. J. Trop. Med. Hyg. 65 (5), 510-517.

Palatnik-de-Sousa, C.B., 2008. Vaccines for leishmaniasis in the fore coming 25 years. Vaccine 26, 1709-1724.

Panaro, M.A., Acquafredda, A., Lisi, S., Lofrumento, D.D., Mitolo, V., Sisto, M., Fasanella, A., Trotta, T., Bertani, F., Consenti, B., Brandonisio, O., 2001. Nitric oxide production by macrophages of dogs vaccinated with killed Leishmania infantum promastigotes. Comp. Immunol. Microbiol. Infect. Dis. 24, 187-195.

Pinelli, E., Boog, C.J., Rutten, V.P., Van Dijk, B., Bernadina, W.E., Ruitenberg, E.J., 1994. A canine CD8+ cytotoxic T-cell line specific for Leishmania infantum-infected macrophages. Tissue Antigens 43 (3), 189-192.

Pinelli, E., Gebhard, D., Mommaas, A.M., van Hoeij, M., Langermans, J.A., Ruitenberg, E.J., Rutten, V.P., 2000. Infection of a canine macrophage cell line with Leishmania infantum: determination of nitric oxide production and anti-leishmanial activity. Vet. Parasitol. 1 (92 (3)), 181-189.
Quinnell, R.J., Courtenay, O., Shaw, M.A., Day, M.J., Garcez, L.M., Dye, C., Kaye, P.M., 2001. Tissue cytokine responses in canine visceral leishmaniasis. J. Infect Dis. 183 (9), 1421-1424.

Rajput, Z.I., Hu, S.H., Xiao, C.W., Arijo, A.G., 2007. Adjuvant effects of saponins on animal immune responses. J. Zhejiang Univ. Sci. B. 8 (3), 153-161.

Reis, A.B., Carneiro, C.M., Carvalho, M.G., Teixeira-Carvalho, A., Giunchetti, R.C., Mayrink, W., Genaro, O., Corrêa-Oliveira, R., Martins-Filho, O.A. 2005. Establishment of a microplate assay for flow cytometric assessment and it is use for the evaluation of age-related phenotypic changes in canine whole blood leukocytes. Vet. Immunol. Immunopathol. 103 (3-4), 173-185.

Reis, A.B., Giunchetti, R.C., Carrillo, E., Martins-Filho, O.A., Moreno, J., 2010. Immunity to Leishmania and the rational search for vaccines against canine leishmaniasis. Trends Parasitol. 26 (7), 341-349.

Rousseau, D., Demartino, S., Ferrua, B., Michiels, J.F., Anjuère, F., Fragaki, K., Le Fichoux, Y., Kubar, J., 2001. In vivo involvement of polymorphonuclear neutrophils in Leishmania infantum infection. BMC Microbiol. 1, 17.

Scott, M.T., Goss-Sampson, M., Bomford, R., 1985. Adjuvant activity of saponina: antigen localization studies. Int. Arch. Allergy Appl. Immunol. 77, 409-412.

Tesh, R.B., 1995. Control of zoonotic visceral leishmaniasis: is it time to change strategies? Am. J. Trop. Med. Hyg. 52, 287-292.

Vanloubbeeck, Y., Jones, D.E., 2004. The immunology of Leishmania infection and the implications for vaccine development. Ann. NY Acad. Sci. 1026, 267-272.

Vouldoukis, I., Bécherel, P.A., Riveros-Moreno, V., Arock, M., da Silva, O., Debré, P., Mazier, D., Mossalayi, M.D., 1997. Interleukin-10 and interleukin-4 inhibit intracellular killing of Leishmania infantum and Leishmania major by human macrophages by decreasing nitric oxide generation. Eur. J. Immunol. 27 (4), 860-865.

Xing, Z., Charters, T.J., 2007. Heterologous boost vaccines for bacillus Calmette-Guérin prime immunization against tuberculosis. Exp. Rev. Vaccine 6 (4), 539-546. 